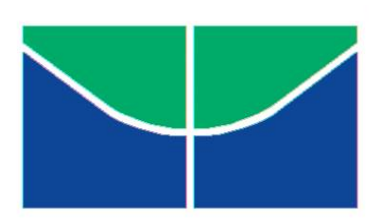

UNIVERSIDADE DE BRASÍLIA

Faculdade de Educação

$\mathrm{UAB} / \mathrm{UnB}$

Curso de Especialização em Educação na Diversidade e Cidadania, com Ênfase em EJA

Parceria MEC/SECAD

\title{
Conhecendo espaços culturais: uma nova forma de aprender e reaprender na EJA
}

MARLA CRISTINA DE LELES PEREIRA

Professora Orientadora: Elizabeth Danziato Rego

Professor Tutor: Airan Almeida de Lima

PROJETO DE INTERVENÇÃO 
Brasília, junho de 2010

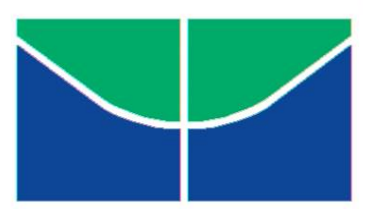

UNIVERSIDADE DE BRASÍLIA

Faculdade de Educação

$\mathrm{UAB} / \mathrm{UnB}$

Curso de Especialização em Educação na Diversidade e Cidadania, com Ênfase em EJA

Parceria MEC/SECAD

MARLA CRISTINA DE LELES PEREIRA

\section{Conhecendo espaços culturais: uma nova forma de aprender e reaprender na EJA}

Trabalho de Conclusão do Curso de Especialização em Educação na Diversidade e Cidadania, com Ênfase em EJA, como parte dos requisitos necessários para obtenção do grau de Especialista na Educação de Jovens e Adultos.

Professora Orientadora: Elizabeth Danziato Rego

Professor Tutor: Airan Almeida de Lima

Avaliador externo: Rogério de Andrade Córdova

Brasília, junho de 2010 
Aos meus queridos alunos de EJA, que nesta jornada de dez anos de trabalho tem me ensinado a ser uma pessoa melhor. 


\section{AGRADECIMENTOS}

Agradeço a Deus o dom da vida e a oportunidade de socializar e vivenciar uma experiência tão rica e espacial

A prof. Beth, que tive o prazer de conhecer e que com seu carinho e competência, me incentivou a concluir este trabalho. Meu muito obrigado.

A gestão e equipe do CEF Agrourbano Ipê, que sempre confiaram no meu trabalho 
A história se desenrola também nos quintais, entre plantas e galinhas, nas ruas dos subúrbios, nas casas de jogos, nos prostíbulos, nos colégios, nas usinas, nos namoros de esquinas. Disso eu quis fazer minha poesia (...) porque só é justo cantar se o nosso canto arrasta consigo as pessoas e as coisas que não tem voz.

Ferreira Gullar 


\section{RESUMO}

O Projeto de Intervenção Local aqui apresentado, foi resultado do trabalho/reflexão realizado em turmas do primeiro segmento de EJA, no Centro de Ensino Fundamental Agrourbano Ipê, localizado na região administrativa do Riacho Fundo -DF, no segundo semestre de 2009. O acesso a espaços e bens culturais, pela comunidade de Jovens e Adultos é raro, ou mesmo inexistente. Diante desta realidade constatada, os objetivos deste trabalho se voltam para atividades que permitam ao aluno ter acesso aos espaços de cultura e bens culturais. Pretende-se levar os alunos para conhecerem espaços culturais como cinema e teatro; realizar rodas de leitura semanais de contos populares e promover momentos de socializações de histórias de vida. Pretende-se ao final de cada uma das atividades realizar um registro escrito coletivamente da experiência vivida. Como parceiros para concretização das atividades propostas, contamos com o apoio dos gestores da escola, bem como dos colegas professores. O projeto deve ser implementado no segundo semestre de 2010.

Palavras-chaves: espaços culturais - Educação de Jovens e Adultos- vivências coletivas. 


\section{SUMÁRIO}

I- Dados de identificação do proponente___ 08

II- Informações sobre o projeto
a. Abrangência
09
b. Público alvo/período de execução
09
c. Ambiente institucional 09 07

III- Projeto de intervenção local

a. Justificativa/Problemática 17

b. Objetivos

22

c. Atividades/cronograma

23

d. Parceiros 24

e. Acompanhamento/avaliação

24

f. Referências

25




\section{I- DADOS DE IDENTIFICAÇÃO DO PROPONENTE}

Nome: Marla Cristina de Leles Pereira

Endereço: Rua 03 Setor dos Engenheiros Casa 03- Metropolitana- DF

Turma: "E"

Professor Tutor: Airan Lima.

Contato: (61) 33866096 e-mail: marlarany @yahoo.com.br 


\section{II- INFORMAÇÕES SOBRE O PROJETO}

\section{ABRANGÊNCIA}

Este projeto será realizado em um Centro de Ensino Fundamental Agrourbano Ipê, localizado no Combinado Agrourbano de Brasília, mais conhecido como CAUB I, em turmas dos primeiro segmento de EJA.

Segundo o Projeto Político Pedagógico desta instituição, a escola precisa voltar-se para as novas realidades, ligar-se no mundo econômico, político, cultural, mas precisa ser um ponto de apoio contra a exclusão social. A luta por uma sociedade justa, uma sociedade com elevada consciência das possibilidades objetivas e subjetivas do homem como ser prático, que inclua a todos que passam pela escola e pelo trabalho dos professores.

A contribuição do Centro de Ensino Fundamental Agrourbano para uma sociedade melhor está no trabalho para a formação geral e continuada de sujeitos pensantes e críticos, na preparação para uma sociedade técnica/científica/informacional, na formação da cidadania crítico-participativa e na formação da ética ${ }^{1}$.

Neste sentido, o presente trabalho pretende contribuir para alcance dos objetivos proposto por esta instituição, com foco nos alunos de EJA primeiro segmento.

\section{PÚBLICO ALVO/ PERÍODO DE EXECUÇÃO}

Um projeto para alunos do primeiro segmento de EJA, com idade ente 18 e 54 anos, que será desenvolvido entre os meses de agosto e outubro de 2010.

\section{AMBIENTE INSTITUCIONAL}

O Centro Ensino Fundamental Agrourbano localiza-se no CAUB I (Combinado Agrourbano I), que, apesar do nome não ser comumente usado, foi transformado em Colônia Agrícola Catetinho em $1998^{2}$.

\footnotetext{
${ }^{1}$ Projeto político Pedagógico, apresentado no ano de 2010, a Secretaria de Educação do Distrito Federal. Elaborado pela equipe gestora: Gedilene Lustosa (vice-diretora) e Sheila Pereira da Silva (diretora)

${ }^{2} \mathrm{O}$ histórico, bem como as informações referentes a instituição foram retirados do Projeto Político Pedagógico- 2010.
} 
O CAUB I foi um modelo de reforma agrária implantado em 1986, no qual foram selecionadas 100 famílias que receberam um lote constituído por uma residência e uma chácara de 6 hectares.

Com a retirada de financiamento pelo governo para os agricultores, muitas chácaras foram vendidas, modificando assim o perfil das atividades econômicas da comunidade. Outro acontecimento que acelerou essa modificação foi o processo de desapropriação de $60 \%$ das chácaras em 1994, pois muitas famílias deixaram de trabalhar com a agricultura.

Quando os agricultores chegaram ao CAUB I, não havia escola e seus filhos tinham que estudar na Escola Classe Ipê. A construção do Agrourbano se iniciou em 1987 com a conclusão da Instituição no mesmo ano.

Com um prédio arquitetado nos moldes das casas do CAUB I, a Escola tinha um telhado colonial e oferecia ensinamentos desde a Educação Infantil à $8^{\underline{a}}$ série do Ensino Fundamental. Duas alunas que nela estudaram, hoje fazem parte do seu corpo Docente; são elas as Professoras Marília Oliveira e Maria Pereira, as quais lecionam em turmas dos anos iniciais do Ensino Fundamental.

O C. E. F. Agrourbano sempre teve uma importante função social. Naturalmente e historicamente se confirmou como uma Instituição de liderança da comunidade em suas demandas sociais. Essa liderança ficou mais clara e presente a partir de 1995, quando a comunidade organizada pela equipe docente da escola pleiteou a reforma e ampliação de seu único prédio, pois este se encontrava com um telhado que proporcionava riscos de desabamento e serviram de moradia para pombos e outros pássaros causadores de danos à saúde - por serem potenciais vetores de doenças - ao corpo discente, composto basicamente por crianças. Tais modificações realizadas na escola naquele ano foram também de suma importância, pois o espaço físico, em virtude do crescimento populacional, não comportava adequadamente seus alunos e não atendia mais a demanda - procura por matrículas da própria comunidade, muito menos as de outras comunidades circunvizinhas, tais como CAUB II, Ponte Alta, Ipê e SMPW.

Com a organização de pais, alunos e demais moradores, por meio do orçamento participativo, além da reforma e ampliação em 1997, a comunidade conquistou iluminação, em 1996. E o asfalto, em 1998 nas principais vias de acesso à escola, e também a conquista de linhas telefônicas para a mesma. Vale salientar que, mesmo antes das modificações, anteriormente citadas, o Agrourbano conseguiu, com muita dificuldade e sob pressão da própria comunidade e daquelas ao seu redor, ampliar seu atendimento oferecendo gradativamente o Ensino Médio, inclusive no turno noturno, que antes só atendia o Ensino Supletivo de $1^{\stackrel{a}{a} \text { a }} 4^{\underline{a}}$ séries. 
Além desse papel social, o Agrourbano foi aos poucos tornando-se uma escola referência, sendo uma das primeiras a implantar o sistema de jornada ampliada - Escola Candanga- para as turmas das Séries Iniciais do Ensino Fundamental em 1997. E também oferecendo projetos de Arte Educação, Corpo e Movimento, Laboratório de Ciências, Laboratório de Informática e Biblioteca não só para as crianças das Séries citadas anteriormente, como também para àquelas da Educação Infantil, além de se destacar com a participação no Projeto Filosofia na Escola, proporcionado pela Universidade de Brasília - UnB.

Desde o início de sua história, o Agrourbano desenvolveu atividades de reflexão sobre a preservação do Meio Ambiente, já que a escola está situada na microbacia do Ipê, próxima às nascentes. Esse trabalho teve um destaque especial em 1995, quando aconteceu a produção de um filme educativo sobre a água, exposto na $1^{\text {a }}$ Bienal da água naquele ano. Muitas outras ações foram implementadas durante vários anos, tais como mutirões de limpeza, cursos de agentes ambientais e mobilização da comunidade para aprovação da lei que transformou a área das nascentes, da microbacia do Ipê, em Área de Relevante Interesse Ecológico.

\section{Objetivos gerais:}

- Promover o desenvolvimento de capacidades cognitivas, operativas e sociais dos alunos (processos mentais, estratégias de aprendizagem, competências do pensar, pensamento crítico), por meio dos conteúdos escolares;

- Promover as condições para o fortalecimento da subjetividade e da identidade cultural dos alunos, incluindo o desenvolvimento da criatividade, da sensibilidade, da imaginação.

- Preparar para o trabalho e para a sociedade tecnológica (saber tomar decisões, fazer análises globalizantes, interpretar informações de toda natureza, ter atitude de pesquisa, saber trabalhar junto etc.);

- Formar para a cidadania crítica, isto é, formar um cidadão-trabalhador capaz de interferir criticamente na realidade pra transformá-la e não apenas formar para integrar o mercado de trabalho;

- Desenvolver a formação para valores éticos, isto é, formação de qualidades morais, traços de caráter, atitudes, convicções e humanitárias. 


\section{Objetivos Específicos:}

- Melhorar a estrutura existente: reforma da cantina, ampliação do depósito de alimentos, organização de espaço para refeitório, organização de espaço para ambiente de convivência e jogos, construção de quadra esportiva etc.

- Fornecer a equipe de professores condições mínimas para o bom desempenho do trabalho pedagógico;

- Valorizar e intensificar a relação escola/comunidade;

- Formar para a cidadania participativa e ética;

- Cumprir as metas do Termo de Compromisso assinado com a Secretaria de Educação do Distrito Federal, melhorando gradativamente a qualidade do ensino;

- Diminuir o índice de repetência em 20\%;

- Elevar o índice de desempenho - IDEB - (Índice de Desempenho da Escola Brasileira) e IDDF (Índice de Desenvolvimento da Educação do Distrito Federal);

- Reduzir em $20 \%$ o percentual dos alunos defasados em idade/série;

- Diminuir a evasão escolar em $20 \%$;

- Garantir acesso e permanência do aluno com necessidade educacionais especiais, preferencialmente em classes comuns;

- Garantir aos alunos o sucesso escolar no prazo legalmente estabelecido por meio da Aprendizagem Significativa;

- Estimular o hábito de leitura;

- Respeitar o desenvolvimento contínuo do aluno, considerando o seu crescimento individual, suas necessidades e potencialidades;

- Valorizar e desenvolver coletivamente práticas avaliativas no processo educacional como aspecto fundamental ao seu aperfeiçoamento;

- Otimizar coletivamente os momentos de planejamento e aperfeiçoamento docente e avaliação como espaço de reflexão e enriquecimento do trabalho pedagógico;

- Valorizar eventos sócio-culturais.

\section{Princípios Epistemológicos}


O CEF Agrourbano propõe-se, através das ações pedagógicas realizadas em seu dia a dia, buscar recursos e meios que atendam às necessidades educacionais de todos os alunos, de modo a oportunizar o seu desenvolvimento e a sua aprendizagem, garantindo educabilidade de todos os seres humanos; direito à equidade, igualdade de oportunidades educacionais independentemente dos comprometimentos que possam apresentar; respeito à dignidade humana; direito à liberdade de aprender e expressar-se e; direito de ser diferente. Dessa forma, incentivará a maior participação de todos, inclusive da família, promovendo ações que levem ao cumprimento ao pleno exercício da Gestão Compartilhada.

Deve-se para tanto, considerar o educando como um ser original e criativo, que aprende na vida social e no espaço escolar, que tem potencialidade e necessidade de interagir e de refletir sobre a diversidade do conhecimento humano, que tem direito de ter acesso ao conhecimento na sua complexidade prática e teórica, que modifica o que sabe, constantemente, que participa da construção do saber escolar e que é um produtor de cultura.

\section{Princípios Didáticos Pedagógicos}

Tendo como princípio a construção de competências pela ação educativa, considerando a aprendizagem como aspecto amplo e tendo o aluno como foco de interesse, o Centro de Ensino Fundamental Agrourbano quer privilegiar na organização do trabalho pedagógico um planejamento interdisciplinar e contextualizado onde a aprendizagem significativa, o incentivo ao hábito de leitura e a avaliação formativa sejam os fios condutores.

Desta forma, pretende-se utilizar a avaliação como ferramenta a serviço dos processos ensino e aprendizagem. Iniciando pela diagnose, pela investigação e visando o levantamento de informações e mapeamento de dados para a compreensão do processo de aprendizagem, vislumbrando intervenções que possam auxiliar os alunos no processo de desenvolvimento de suas competências, bem como no crescimento da sua autonomia.

\section{Princípios Éticos}

No campo da ética, o mundo contemporâneo convive com uma crise de valores, predominando um relativismo moral baseado num interesse pessoal, na vontade, na eficácia, sem referências a valores humanos como a dignidade, a 
solidariedade, a justiça, o respeito à vida. É preciso a colaboração da escola para a revitalização da formação ética atingindo tanto as ações cotidianas quanto as formas de relações entre povos, etnias, grupos sociais, no sentido do reconhecimento das diferenças e das identidades culturais. É importante lembrar que, o papel da escola é de colaborar, dando seqüência, à educação que seus alunos recebem de suas famílias.

A formação de cidadãos e cidadãs é, ao mesmo tempo, um desafio ético e político. No desafio ético de formação cidadã, se põe em jogo o caráter constitutivamente político da ação educativa. Assim, pensar em educação da cidadania significa pensar em valores, normas e direitos (não apenas legais, senão também morais) que configuram a práxis cidadã e que, devem constituir a práxis educativa.

Assim sendo, os temas relacionados à Ética e Cidadania devem estar presentes tanto correlacionados aos componentes curriculares como nas reflexões sobre o cotidiano e ações das pessoas que fazem parte do convívio escolar, pois preparar para a cidadania ética supõe práticas escolares dentro destes princípios, sem as quais, torna-se um discurso vazio.

\section{ORGANIZAÇÃO ADMINISTRATIVA}

O Centro de Ensino Fundamental Agrourbano, funciona nos turnos matutino, vespertino e noturno, com as seguintes modalidades de ensino:

\begin{tabular}{|c|c|c|}
\hline MATUTINO & VESPERTINO & NOTURNO \\
\hline $\begin{array}{l}\text { Ensino Fund. Anos Finais } \\
\text { Sala de Recursos }\end{array}$ & $\begin{array}{l}\text { Ensino Fund. - Séries } \\
\text { Finais } \\
\text { Ensino Fund. Anos Iniciais } \\
\text { Sala de Recursos }\end{array}$ & Ed. de Jovens e Adultos \\
\hline $\begin{array}{l}\text { Uma turma de } 5^{\text {a }} \text { série }=24 \\
\text { alunos }\end{array}$ & $\begin{array}{l}\text { Duas turmas de } 5^{\text {a }} \text { série }=63 \\
\text { alunos }\end{array}$ & $\begin{array}{l}\text { Quatro turmas de } 1^{0} \\
\text { segmento }=32 \text { alunos }\end{array}$ \\
\hline $\begin{array}{l}\text { Duas turmas de } 6^{\mathrm{a}} \text { série }=53 \\
\text { alunos }\end{array}$ & $\begin{array}{l}\text { Uma turma de } 1^{\circ} \text { ano do BIA } \\
=29 \text { alunos }\end{array}$ & \\
\hline $\begin{array}{l}\text { Uma turma de } 7^{\text {a }} \text { série }=40 \\
\text { alunos }\end{array}$ & $\begin{array}{l}\text { Uma turma de } 2^{\circ} \text { ano do BIA } \\
=23 \text { alunos }\end{array}$ & \\
\hline Uma turma de $8^{a}$ série $=36$ & Uma turmas de $3^{\circ}$ ano do BIA & \\
\hline
\end{tabular}




\begin{tabular}{|c|c|c|}
\hline alunos & $=36$ alunos & \\
\hline Ensino Médio & $\begin{array}{l}\text { Duas turmas de } 3^{\text {a }} \text { série }=45 \\
\text { alunos }\end{array}$ & \\
\hline $\begin{array}{l}\text { Uma turma } 1^{\text {a }} \text { série }=41 \\
\text { alunos }\end{array}$ & $\begin{array}{l}\text { Uma turma de } 4^{\mathrm{a}} \text { série }=30 \\
\text { alunos }\end{array}$ & \\
\hline $\begin{array}{l}\text { Uma turma } 2^{\mathrm{a}} \text { série }=25 \\
\text { alunos }\end{array}$ & & \\
\hline $\begin{array}{l}\text { Uma turma } 3^{a} \text { série }=25 \\
\text { alunos }\end{array}$ & & \\
\hline Total de Turmas: 08 & Total de Turmas: 08 & \\
\hline Total de alunos: 244 & Total de alunos: 226 & \\
\hline $\begin{array}{l}\text { Sala de Recursos: atende } \\
\text { alunos } 10 \text { alunos ANNE - } \\
\text { dos Anos Iniciais }\end{array}$ & & \\
\hline & Total Geral: 502 & \\
\hline
\end{tabular}




\section{III- PROJETO DE INTERVENÇÃO LOCAL}

\section{JUSTIFICATIVA}

O jovem e adulto trabalhador que procura a escola traz um desejo certo de que quer aprender a ler e escrever. Junto a isto, traz as marcas vividas pela opressão, de uma sociedade letrada, que marginaliza e desrespeita.

Seu corpo e sua fala trazem este sentimento de inferioridade bem marcados: cabeça baixa, corpo encurvado, e o cansaço constate de uma vida de luta e trabalho. Muitos acreditam fortemente que são inferiores por não dominar o código escrito ${ }^{3}$.

Vale ressaltar, que quando falamos em Educação de Jovens e Adultos, precisamos pensar em pelo menos três aspectos: "a condição de não crianças, a condição de excluídos da escola e a condição de membros de determinados grupos culturais" (Oliveira, 2002).

O jovem e adulto exige uma especificidade pedagógica de acordo com sua condição. A infantilização ou mesmo a mera transposição do que é trabalhado no currículo do ensino fundamental para o EJA, é um desrespeito a estas pessoas. Nosso curso muito contribuiu nesta discussão ao apontar a necessidade de um currículo próprio para EJA.

A condição de excluídos da escola, é uma situação que ultrapassa os muros escolares e se marca na própria sociedade. Vivemos em uma sociedade letrada e excludente. Quem não domina o código da escrita, fica a margem socialmente.

Não saber ler e escrever é um estigma. Ferida interna e marca visível, difícil de esconder. Em matéria da Revista Carta Capital, encontramos relato de algumas pessoas que vivem nesta situação de marginalidade :

"Parece que a gente pensa que está escrito na testa da gente. $O$ jeito da gente caminhar, o jeito de pegar numa coisa, o jeito da gente se sentar na mesa, de se servir. Quando a gente vai falar uma coisa, a pessoa não entende do jeito que a gente fala, porque as vezes a gente fala de um jeito, quem já sabe ler fala de outro jeito."(Mulher de 30 a 40 anos, MA)

\footnotetext{
${ }^{3}$ Ver Freire, Paulo Pedagogia do Oprimido, Paz e Terra, 1987.
} 
“A população analfabeta. Não somos nada. Nada. O desemprego está demais, ainda mais para estas pessoas que não sabem ler e nem escrever" (Homem 40 anos, MT)

"Eles acham que porque é analfabeto não precisa se vestir, não precisa se calçar, não precisa de dormir, não precisa se agasalhar, não precisa se divertir. Não é? ( Mulher de 30 a 40 anos, Ribeirão das Neves - MG)

Estes depoimentos, recolhidos pelo MEC num estudo feito em 2004, mostram na fala destas pessoas as marcas que a exclusão social fazem em suas vidas. ${ }^{4}$

Em sala de aula, é comum os alunos chegarem com o discurso de que vão estudar para serem alguém, numa clara demonstração de menos valia, de baixa estima. É a marca da exclusão, do oprimido que reconhece está condição. (Ver Freire, Pedagogia do Oprimido, 1987)

Diante deste sentimento de inferioridade, procurar a instituição escolar exige um movimento de coragem. A coragem de assumir uma condição marginalizada que é a de ser analfabeto. Para muitos, que conseguem permanecer e dar continuidade aos estudos, a despeito de todas as dificuldades diárias, encontram na escola um espaço de convivência social. Esta instituição se torna não só um lugar para aprender a ler e escrever, mas um espaço de construir amizades, de conversa, de troca de experiência. Momentos de encontros, no qual reconhecem pares que vivem a mesma situação de vida.

Esta condição histórica do jovem e adulto, nos leva as várias discussões tratadas durante todo o curso: sua condição histórica e de trabalhador, a condição inadequada da escola e de seus profissionais, a ausência de um currículo específico, enfim, a própria organização da escola que é concebida originalmente para crianças e adolescentes.

Em cada um destes aspectos, poderíamos discorrer e desenvolver inúmeros pontos de vista. Todavia, a proposta aqui neste projeto, é levantar a partir a minha prática enquanto professora alfabetizadora de jovens e adultos da rede pública de ensino do Distrito Federal, questões para desenvolver um projeto interventivo.

Diante desta complexidade e diversidade, passei a questionar o que elegeria para estudo e análise e que ao mesmo tempo contemplasse a ânsia e desejo de resolver os problemas que existem na prática pedagógica diária do professor de EJA na Secretaria de Educação do Distrito Federal.

Lacerda (2002) p. 75 , com propriedade me lembra que

"aprendemos em nossa formação a desenvolver um olhar distanciado das questões que nos afligem, e a buscar fora delas às muitas respostas que

\footnotetext{
${ }^{4}$ No ano de 2004, o MEC fez uma pesquisa em diferentes cidades das cinco regiões brasileiras com objetivo de ouvir as pessoas analfabetas. Parte deste estudo, foi matéria da revista Carta Capital neste mesmo ano. Os depoimentos deste trabalho, foram retirados desta matéria.
} 
poderiam nos ajudar a resolvê-las. Respostas construídas por um outro, que não nós mesmos, mediadas por um conhecimento não gerado por entre as angústias, dúvidas e incertezas, com as quais nos deparamos continuamente"

No meu entender, identificar uma problemática na sua realidade e traçar caminhos de solução, vai ao encontro da idéia de que o micro se reflete no macro e de que enquanto professores reflexivos, pensadores sobre a sua prática, podemos pensar/repensar e construir novas possibilidades de trabalho.

Assim, ao privilegiar determinada questão, podemos tocar em outras.

Enquanto educadores, possuímos inúmeras experiências, vividas na prática docente. Junto a esta experiência, todo um conhecimento prático tecido em meio ao cotidiano da escola, a inúmeros referenciais teóricos, além do conhecimento que dispomos do universo escolar, adquirido durante nossa trajetória enquanto estudantes (Lacerda, 2002)

O cotidiano escolar, esfera de formação repleta de sentido, vem nos formando em meio a situações que não se encontram no manual, o que pressupõe o fortalecimento de competências que venham construir uma identidade que seja marcadamente reflexiva e emancipatória (FREIRE, 1997).

Assim sendo, um projeto de intervenção local, proposta deste curso, nos permite pensar sobre esta realidade e aliado aos conhecimentos práticos e teóricos, construir uma nova possibilidade pedagógica. Uma possibilidade refletida a partir do real que aponta para possibilidades.

Neste sentido, meu PIL se voltou para uma questão vivenciada concretamente pelos jovens e adultos com os quais trabalho e que está ligado ao acesso aos meios e bens culturais.

Sabemos, como apontado por Oliveira (2002), Freire (1996), Lacerda (2002) e outros autores, que estes sujeitos trazem suas marcas culturais, ainda que estas sejam desrespeitadas e não muitas vezes na cultivadas.

Porem, o acesso a muitos dos bens culturais e espaços de cultura é negado a esta população, assim como a grande maioria da população pobre deste país. É preciso ter dinheiro para ter acesso cultural e enquanto trabalhadores, o dinheiro recebido mal dá para alimentação, vestuário, enfim as necessidades básicas.

Identifiquei assim, que a grande maioria dos alunos, só tem a escola e a igreja como espaços diferenciados de convivência social. A ausência de um espaço cultural próximo, bem como de atividades lazer na vida dos alunos, me suscitou o desejo de 
realizar atividades que permitissem a socialização de experiências pessoais e a vivencia de momentos prazerosos e culturais seja na escola ou fora dela.

O presente Projeto de Intervenção Local tem como objetivo central levar os alunos a espaços culturais como teatros, cinemas, museus, além de realizar no âmbito escolar atividades que garantam ao aluno este acesso cultural.

É preciso desmistificar para comunidade local/escolar, especificamente nós educadores, bem como para aluno trabalhador jovem e adulto, que o conhecimento só acontece na sala de aula e associado somente ao processo de leitura e escrita ${ }^{5}$.

Paulo Freire, nosso eterno educador, já nos lembra que o ensino não acontece somente em sala de aula, e na relação entre professor e aluno. "Ensinar não é tranferir conhecimento, mas criar as possibilidades para sua produção ou sua construção" (Freire, 1996, p.25)

$\mathrm{O}$ acesso aos bens culturais, em atividades como estas, levam o aluno a perceber que ele faz parte de uma cultura, de uma sociedade e que enquanto sujeito histórico e cidadão, tem muito a contribuir com sua experiência.

O uso da oralidade e a oportunidade dada ao jovem e adulto de se expressar, elevam a estima do sujeito e ele começa e se perceber importante e a si valorizar. Além de ampliar os horizontes no que diz respeito ao conhecimento.

Com esta prática, a comunidade escolar passa a perceber que a prática pedagógica precisa extrapolar os muros da sala de aula.

Para o trabalhador jovem e adulto, as marcas do trabalho pesado, da luta diária são tão fortes, que é difícil perceber que uma atividade cultural diferenciada pode nos dar um descanso.

Acredito que todas estas atividades podem favorecer o crescimento pessoal, o reconhecimento enquanto sujeito e valorização de si e do processo de autonomia.

\footnotetext{
${ }^{5}$ Para aprofundar, ver Machado (2007), que trata de questões referentes ao Pensamento de Paulo Freire e políticas públicas de EJA.
} 
OBJETIVO GERAL

- Realizar permanentemente atividades de cunho cultural, que permitam aos alunos ter acesso aos bens culturais, seja com atividades extra-classe e vivencias coletivas teatrais.

\section{OBJETIVOS ESPECÍFICOS}

- Levar os alunos para conhecerem espaços culturais como cinema e teatro.

- Realizar rodas de leitura semanais de contos populares

- Promover rodas de "causos" e histórias de vidas 


\section{ATIVIDADES/CRONOGRAMA}

Para realização do projeto, proponho a realização das seguintes atividades:

\section{- Semanalmente}

- Contação de histórias populares uma vez por semana no pátio da escola (livro Base- No meio da noite Escura tem um Pé de maravilha- Ricardo de Azevedo).

- socialização de vivências pessoais e histórias de vida.

- registro coletivo escrito das atividades para publicação de um livro.

\section{- Agosto}

- Preparação de uma apresentação teatral a partir do conto popular "O espelho" (releitura de Ricardo de Azevedo)

- Assistir um filme em sala de cinema da cidade de Taguatinga

\section{- Setembro/outubro}

- Leitura de contos populares Indígenas e Africanos e preparação de encenações teatrais

- Ir ao teatro do Complexo da Funarte- próximo a torre de TV.

\section{-Outubro}

- Visita a uma exposição no Centro Cultural do Banco do Brasil- CCBB 


\section{PARCEIROS}

Para realização do projeto, alguns parceiros serão importantes para execução do mesmo:

- gestão da escola- dando suporte pedagógico, estrutural e apoio nas atividades do projeto

- os colegas de trabalho- parceiros, sem os quais as atividades coletivas não poderão acontecer.

- Sindicato dos Professores do Distrito Federal - SINPRO- auxilio quanto ao transporte dos alunos nas atividades fora da escola.

\section{ACOMPANHAMENTO E AVALIAÇÃO}

Para avaliação e acompanhamento do projeto, pretendo registrar em um diário pessoal as impressões, sentimentos e resultados.

Outro instrumento importante será a avaliação realizada após cada atividade, seguida de um registro que pode ser coletivo ou individual, feito em sala pelos alunos e professora. Ao final do projeto, pretende-se transformar estes registros em um livro.

Importante destacar que um dos objetivos maiores do curso é a constituição de uma comunidade de trabalho/aprendizagem em rede na diversidade -CTARD. Neste sentido, este Projeto de Intervenção local, resultado das discussão/reflexão da prática enquanto educadora, só foi possível de acontecer devido a existência deste espaço de socialização.

Assim sendo, acredito que não deva ficar restrito ao tempo de duração do curso. Que a experiência vivida, entre nós educadores e educando, possa se estender a uma socialização constante das experiências na EJA no DF e que esta Comunidade se amplie ainda mais. 


\section{REFERENCIAS BIBLIOGRÁFICAS}

FREIRE, P. Pedagogia da Autonomia: Saberes necessários à prática educativa. São Paulo: Paz e Terra, 1996

FREIRE, Paulo Pedagogia do Oprimido, 17ed. Rio de Janeiro, Paz e Terra, 1987.

OLIVEIRA, Marta Kohl - Jovens e Adultos como sujeitos do conhecimento a aprendizagem in RIBEIRO, Vera Educação de Jovens e Adultos- Novos Leitores, novas leituras, Campinas, SP: Ação Educativa, 2002.

LACERDA, Mitsi Por uma formação repleta de sentido in ZACCUR, Edwiges e ESTEBAN, Maria Tereza(orgs) - Professora- pesquisadora, uma práxis em construção, Rio de Janeiro: DP\&A, 2002.

MACHADO, Maria Margarida, A atualidade do pensamento de Paulo Freire e as políticas de Educação de Jovens e Adultos "o saber de experiência feito" Camões e Paulo Freire, in Revista de Educação de Jovens e Adultos, v. 1, p.1117, dez/2007.

LUSTOSA, Gedilene e SILVA, Sheila (equipe gestora) - Projeto Político Pedagógico do Centro de Ensino Fundamental Agrourbano Ipê. Documento apresentado a Secretaria de Estado de Educação do Distrito Federal no ano de 2010. 